\title{
Gisele Lorenzetti
}

\section{entrevista}

\section{Gisele Lorenzetti}

- Diretora-executiva da LVBA Comunicação

- Bacharel em Comunicação Social com habilitação em Relações Públicas pela FAAP

- Especialista em Administração de Empresas

- gisele.lorenzetti@lvba.com.br

Entrevistadores

Cyro Augusto Pachicoski Couto

Luiz Alberto de Farias

Paulo Celestino da Costa, filho 


\section{Os desafios de avaliar o intangivel}

Como medir o intangível? Pode ser um paradoxo, mas esta é hoje uma das principais missões de Gisele Lorenzetti à frente da LVBA Comunicação como diretora-executiva. Angústia e inconformismo em não quantificar os resultados obtidos com as ações de comunicação foram o que levaram a LVBA a propor o desenvolvimento de uma ferramenta de mensuração, o Índice de Desempenho Institucional - IDI ${ }^{\circledR}$.

Construído a partir de uma visão objetiva da comunicação e tendo o planejamento estratégico como pedra fundamental, o IDI ${ }^{\circledR}$ envolveu profissionais de Relações Públicas, Jornalismo, Matemática e Economia em uma equipe multidisciplinar na sua criação. Já em aplicação em clientes após dois anos de desenvolvimento, a diretora-executiva ressalta: $\mathrm{o}$ IDI ${ }^{\circledR}$ não é só uma ferramenta, é um instrumento de gestão de comunicação corporativa.

Formada em Relações Públicas pela FAAP, Gisele é especialista em Administração de Empresas e teve a oportunidade de passar por todas as áreas da agência até chegar à diretoria, em 1990. Também apresenta no seu currículo a vivência acadêmica como professora de Planeja- mento em Relações Públicas na Faculdade de Comunicação Cásper Líbero. Quase trinta anos depois de criada a LVBA pelo seu pai, Valentim Lorenzetti, Gisele agrega uma visão prática e objetiva na direção da agência ao lado de Flávio Valsani, também diretor-executivo.

Gisele falou à Organicom na sede da LVBA, abrindo um pouco do segredo (guardado a sete chaves) do método de mensuração criado por sua agência, da importância do planejamento e das suas vivências dentro e à frente de uma das mais antigas agências de comunicação brasileiras. Para ela, a mensuração é o principal desafio encontrado pela comunicação atualmente e quem não apresentar boas soluções está fadado ao insucesso.

- Organicom - A partir de sua experiência com a administração e lidando diretamente com o empresariado, a mensuração é a única linguagem para acessar os gestores?

- Gisele Lorenzetti - A palavra mensuração é conseqüência, é final de processo. Tudo começa quando o profissional e o cliente - mas principalmente o profissional - pensam estrategicamente na 
comunicação. Se for vender só uma ferramenta, não se está pensando de forma estratégica e não se tem como comprovar resultados, como mensurar. Só se pode mensurar alguma coisa sabendo onde se quer chegar. E isso só se consegue com um planejamento estratégico. Ou seja, tudo gira em torno dele. A partir daí, desenvolver ferramentas de gestão da comunicação e de mensuração de resultados é uma conseqüência. A grande dificuldade dos profissionais de comunicação é conseguir não apenas mensurar, mas classificar toda a sua produção em números, o que a maioria do mercado exige, de uma certa forma.

- Organicom - Sua experiência mostra que esse posicionamento, de se pensar estrategicamente, tem surtido efeito?

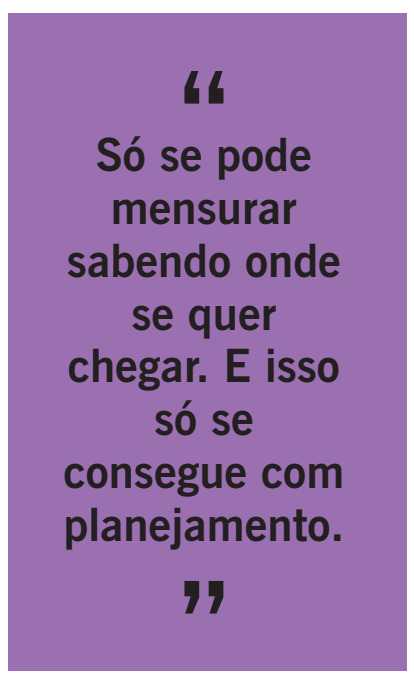

\section{- Gisele Lorenzetti -}

Tem. No ano passado ganhamos algumas concorrências porque o cliente pedia assessoria de imprensa e nós oferecíamos algo com mais valor agregado, deixando claro que a assessoria não é a solução para todos os males e que é necessária uma outra visão. Ao cliente, ao empresário, tudo é permitido pedir. Ele percebe que sua empresa tem carências em comunicação e não sabe, exatamente, quais. É o profissional de comunicação que deve entender melhor como funciona a empresa, como melhorar a comunicação interna e a relação com os demais públi- cos. Isso é vender de forma responsável, sendo profissional, passando ao cliente a necessidade real que ele tem. Não raro, em vários momentos, eu acho que a assessoria de imprensa não é o que a empresa precisa. Ela necessita antes de um trabalho de comunicação interna, de uma relação mais direta com os públicos. Vamos ver quem são eles e o que podemos fazer. O que precisa é um "tirinho" de espingarda e não de tiro de canhão. E quando a argumentação é lógica, o cliente entende.

- Organicom - Quais são as bases para conseguir construir esse diagnóstico e fazer essa proposição para a organização? E como é a abertura dos clientes para que se conclua um diagnóstico?

- Gisele Lorenzetti Certamente o diagnóstico é parte fundamental de um planejamento de comunicação. Uma pesquisa em profundidade ou a auditoria de opinião são importantíssimas para conhecermos a percepção dos públicos em relação à empresa. Nem sempre isso é possível. As empresas clientes ainda têm dificuldade em reconhecer que pesquisa é fundamental para o trabalho das agências. Neste caso, usamos tudo o que a empresa já dispõe em termos de pesquisa; usamos ferramentas eletrônicas que permitem complementar este diagnóstico e entrevistamos algumas pessoas-chave a fim de enrique- 
cermos o cenário e chegarmos a um diagnóstico. Um verdadeiro planejamento tem que ter o diagnóstico como base. Além disso, trabalhar a partir de um bom diagnóstico é o melhor dos mundos - é construir um plano de ações a partir de alicerces sólidos.

- Organicom - Planejamento, às vezes, pressupõe trabalhar a longo prazo. As empresas hoje estão dispostas a trabalhar com prazos mais longos?

- Gisele Lorenzetti - Depende do que estas empresas buscam. Se a necessidade é de vender mais e rapidamente, nada como um bom trabalho de promoção de vendas; se a necessidade é ser reconhecido de forma massificada, nada como um bom trabalho de propaganda. Mas se a necessidade for criar e manter um relacionamento junto aos públicos de interesse da empresa, não há como ser imediatista. Assim como em nível pessoal não travamos relacionamento a partir de um único contato, o mesmo se dá com as empresas. Relacionamento pressupõe sistemática e freqüência e isso pode ser traduzido em médio ou longo prazos.

- Organicom - Então os resultados realmente são sempre medidos a médio e a longo prazos?

- Gisele Lorenzetti - De certa forma $\operatorname{sim}$. Mas vale aqui pensarmos um pouco no que significa longo prazo. Hoje não consigo me imaginar vendendo um projeto e falando que no quarto ano começaremos a ter um trabalho de Relações Públicas perfeito. Hoje, o mundo on line ofereceu recursos como a Internet, que aceleraram os processos, e isso tem que conspirar a seu favor. É um pouco do que falou o Ramiro na edição anterior da Organicom [Ramiro Prudêncio, presidente da Burson Marsteller no Brasil]. Só que quando falamos em relacionamento, falamos em tempo. Credibilidade é construída com tijolinhos que você vai colocando um após o outro. A construção é lenta e qualquer um destrói isto facilmente num pontapé ou com uma chuva mais forte. O planejamento não é a ferramenta que vai fazer com que este prazo seja mais longo - é sim a peça que vai dar mais alicerce à construção. Ao meu ver, o planejamento vai permitir que tudo tenha coerência e que seja feito de acordo com uma necessidade predeterminada. Portanto, quanto se fala em planejamento, se fala em organização e eficiência e não em prazo. E é a partir dele que você vai poder medir os resultados.

- Organicom - Quais foram as motivações que levaram a LVBA a criar o Índice de Desempenho Institucional - IDI ${ }^{\circledR}$ ?

- Gisele Lorenzetti - Angústia e inconformismo foram os motivos. A LVBA tem, hoje, 29 anos no mercado, e é interessante pensar como as coisas mudaram desde então. No início, e durante muito tempo, vendíamos ferramentas também intangíveis. Chegávamos para o cliente e falávamos: "o que vendemos é comunicação institucional e isso é não tangível, não mensurável. Traz ganhos à corporação, mas não conseguimos medir". Com o passar do tempo isso começou a nos incomodar, pois o mundo mudou. As organizações passaram a ser globais e o discurso presente é a geração 
de retorno aos acionistas. Além disso, os CEOs (Chief Executive Officer) são profissionais especializados em finanças e não em filosofia, quando então, poderia se aceitar com mais facilidade algo não tangível e não mensurável. Tínhamos de lidar com essa realidade e chegamos à conclusão de que não dava mais para vender o não tangível. Então montamos um grupo multidisciplinar com pessoas de comunicação e também administradores, economistas, estatísticos. A primeira tarefa deles foi tirar a subjetividade. Costumo dizer que nossa formação toda é em Word. Nós pensamos textos, mas o mundo migrou para o Excel e tivemos de migrar junto. O grupo foi muito importante para ajudar a traduzir um planejamento numa planilha. O segundo estágio foi descobrir como ponderar, como dizer qual ação é mais importante, quanto ela pesa, qual sua contribuição efetiva dentro do planejamento. Cada ação tem que atingir o objetivo estratégico. A partir disso, criam-se metas e índices: o índice atual, o índice meta, o ín- dice mensal, que são comparados. Ou seja, é preciso tirar a subjetividade e só é possível ter, com clareza, uma meta numérica. $\mathrm{O}$ discurso atual de mensurar resultado é conseqüência de uma organização anterior, de um planejamento estratégico.

- Organicom - E como é que tem sido a percepção dos seus clientes?

— Gisele Lorenzetti - É algo novo, estamos criando um novo conceito. Temos feito apresentações do IDI ${ }^{\circledR}$ para empresas e grupos de empresários e percebemos que a mensuração de resultados está chegando como necessidade na área de comunicação. E isso se dá por conta de uma outra tendência nas organizações: o BSC (Balanced Scorecard). É uma metodologia surgida para administrar a gestão dos ativos intangíveis, quando as empresas começaram a ver que eles tinham peso muito forte no sucesso dos negócios e no alcance das estratégias. $\mathrm{O}$ BSC nasce realmente para medir a eficá-

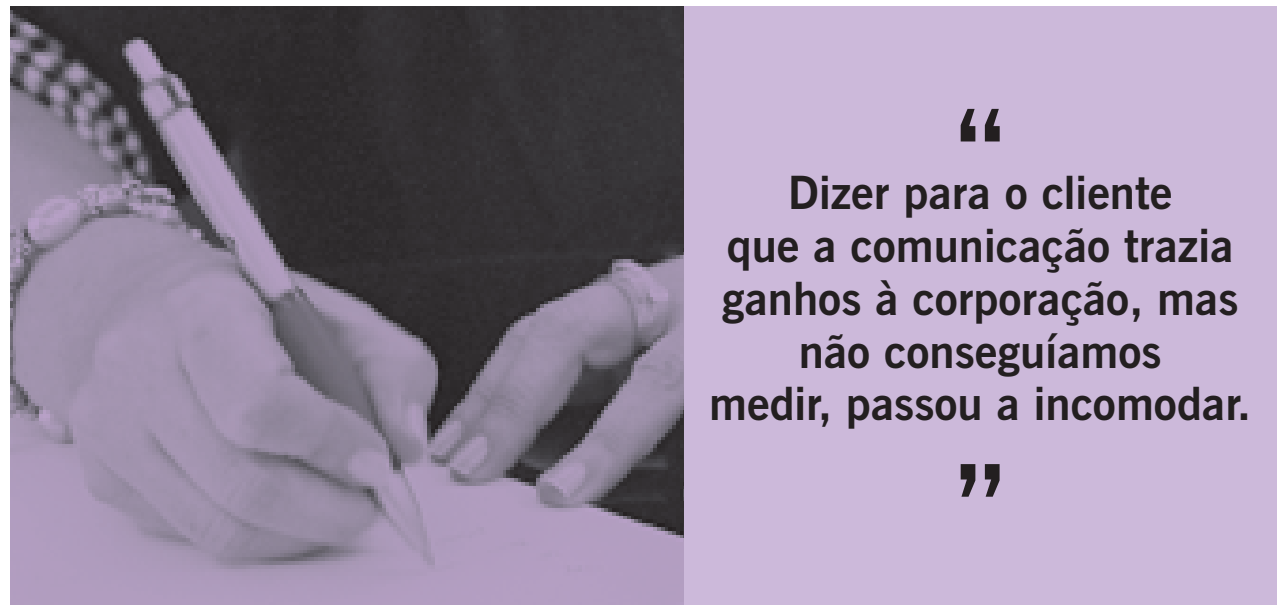


cia dessas ações, sempre com foco na estratégia. É uma teoria surpreendente, pois se não há uma estratégia clara, não se tem como medir resultados. Nosso Índice é muito inspirado no BSC.

- Organicom - Além da análise quantitativa, ele se propõe a abarcar o qualitativo também?

- Gisele Lorenzetti - O objetivo do IDI ${ }^{\circledR}$ é ser um método quantitativo. Uma ferramenta de mensuração de resultados e isso é inovador. Métodos de avaliação qualitativos já existem alguns. Além disso, a pesquisa é sempre uma excelente ferramenta para isso. Temos que lembrar, também, que o maior valor do IDI ${ }^{\circledR}$ vai além da mensuração. Trata-se de uma ferramenta de gestão da comunicação cujo objetivo principal é o de não permitir que as ações se desprendam dos seus objetivos estratégicos. O que muitas vezes acontece, com uma certa freqüência, é que o plano de ação cria pernas próprias. Por exemplo, uma newsletter nasceu para cumprir um determinado objetivo e, para isso, deve ter determinadas características. Na terceira edição, a publicação, criando as tais pernas próprias, passa a ter, por exemplo, um espaço dedicado à criança, porque o editor achou que isso era uma carência. Aí fica a dúvida: era mesmo uma carência? Este era um público que interessava à empresa naquele momento? Que mensagens queremos endereçar a este público? A Matriz de Desempenho Institucional ${ }^{\circledR}$ que é a base do IDI $^{\circledR}$ responderia essas questões.

- Organicom - É o feedback do plano de ação que permite a mensuração?
— Gisele Lorenzetti - Não. É manter o plano de ação em total e permanente sintonia com o planejamento de comunicação que gera a mensuração. Só podemos medir quando sabemos onde queremos chegar - este é o papel do planejamento, dar a direção. O IDI ${ }^{\circledR}$ é o check list e o relatório do vôo - ele serve para orientar o processo e para contar como foi a viagem.

- Organicom - O IDI ${ }^{\circledR}$ abrange a comunicação interna e a externa? Como se dá a medição?

- Gisele Lorenzetti - As duas juntas. A partir do momento que se tem uma ação e ela está dentro de uma necessidade estratégica, temos que ser capazes de definir os atributos e os parâmetros de mensuração. A priori, não existe uma planilha básica para mensuração. A partir de cada ação serão definidos os parâmetros que serão medidos. Para qualquer ação você tem que medir, mesmo porque não existe ação fora da estratégia, sem mensagens para passar. No caso de medir um evento, por exemplo, podemos avaliar desde a qualidade do mailing de convidados até a presença das mensagens preferenciais em todas as etapas deste evento. Tudo isso são itens que você pode ponderar e avaliar. Mas o mais importante é se o evento foi uma ação definida dentro de uma necessidade estratégica. Se foi definido no planejamento estratégico o relacionamento que se quer ter com cada público, com quem se quer se relacionar, com quais mensagens e ferramentas, tudo isto tem de ser colocado quantitativamente.

- Organicom - A implantação do IDI ${ }^{\circledR}$ é difícil? 
- Gisele Lorenzetti - Difícil não, mas complexa. Para isso temos o grupo multidisciplinar e na fase de implantação a presença do profissional de ciências exatas é fundamental para tirar a subjetividade e traduzir o planejamento numa Matriz. É fundamental aqui lembrarmos que não deixamos de ser profissionais de comunicação, não perdemos a emoção e não deixamos de construir a nossa rede de afetividade. Ela está lá quando se define o plano, quando são criadas ações diferenciadas. Tem que ter criatividade; não podemos esquecer nunca disso. Mas temos de ser criativos em ações que geram resultados. Não é fácil desconstruir as verdades do inteligível, do mensurável e do qualitativo. A Margarida Krohling Kunsch já ensinava isso também, mas ela sempre colocou a avaliação como sendo um ponto fundamental.

- Organicom - O índice é específico de cada empresa?

- Gisele Lorenzetti - Ele é totalmente customizado, porque cada empresa tem uma necessidade específica na comunicação, tem um valor a dar a ela e uma maneira de ver e comunicar com instrumentos diferentes. Ele é totalmente desenhado um a um, pois a cultura empresarial influencia muito. Tenho que levar em consideração cada parte de uma estrutura organizacional.
- Organicom - E como está o Índice hoje?

- Gisele Lorenzetti - O IDI ${ }^{\circledR}$ passou por algumas mudanças desde os primeiros estudos, mas agora está fechado. Inclusive, o índice já se encontra registrado na Biblioteca Nacional A fase mais complicada é a inicial, de definição das matrizes: elaborar, traduzir as ações da planilha e ponderar. Esses ajustes levam em torno de três meses. O tempo de desenvolvimento do Índice foi de dois anos. Hoje temos aprimorado mais a forma de apresentação, mas a metodologia está fechada, definida. O BSC foi usado como benchmarking. A Companhia de Notícias CDN também tem um índice muito interessante, que avalia a presença, a reputação da empresa pela imprensa e considera vários outros itens. Esses dois movimentos, da CDN e da LVBA, em torno da mensuração, se deram juntos, tanto que construímos esses instrumentos quase na mesma época.

- Organicom - Como o clipping é visto no $\mathrm{IDI}^{\circledR}$ ?

- Gisele Lorenzetti - Se o trabalho prevê a análise do trabalho de relações com a imprensa, o clipping não pode ser deixado de lado. Mas tem de se medir também o não-clipping. Uma matéria que 
não foi publicada, fruto de um trabalho profissional junto à imprensa, tem um valor e também precisa ser medida. O clipping pode ser medido a partir de parâmetros como presença de key messages, clareza do porta-voz, perfil de quem escreveu, o peso e a abrangência geográfica do veículo, a editoria em que saiu, se foi pró-ativa, reativa, se foi positiva ou negativa, se teve entrevista, citação de fonte, mensagem preferencial presente. Isso é medir o clipping. Não dá para colocar na balança que pesou "dez quilos" de clipping. Voltando à boa e velha tecla do planejamento: vamos partir do princípio de que o trabalho de assessoria que está sendo realizado é fruto de uma necessidade estratégica. Assim sendo, é isso que eu posso e devo medir: esta ação está, de fato, gerando os resultados buscados?

- Organicom - Como você encara a questão do marketing nesse processo?

— Gisele Lorenzetti - Eu tenho uma visão muito clara do que é marketing. Ele não conflita conosco de forma alguma, pois a área de marketing é nosso cliente. As ações de comunicação podem ser movidas em apoio ao marketing e em conjunto com ele para o desenvolvimento do produto e entendimento desde o primeiro momento de qual é a missão, o que se espera dele, definir quais serão as ações de comunicação com o público dirigido, se vão dar apoio ao lançamento etc. Portanto, não vejo como conflito e sim como uma ação conjunta assim como a propaganda.

- Organicom - E como você vê a publicidade hoje em dia?
- Gisele Lorenzetti - Creio que houve uma desaceleração ou queda no investimento nesses últimos tempos. Isso pode estar associado às diversas transformações no macro-ambiente e à própria mudança dos empresários que passaram a entender o que é e como utilizar a publicidade. Hoje eles sabem que, com um pouco menos de verba, podem contar com outros meios para maximizar a ação. $E$ isso foi o grande trampolim para a atividade de Relações Públicas. Google, Submarino, Viagra, Botox, Linux, Yahoo, Amazon, todas essas marcas foram construídas sem investimentos publicitários. Linux jamais terá, pois não tem dono. Botox e Viagra são marcas que, inclusive, não podem ter investimento publicitário diretamente por força da legislação vigente do Ministério da Saúde no Brasil. Mas são todas marcas que estão se consolidando.

- Organicom - É um pouco do que o Al Ries fala?

- Gisele Lorenzetti - Não vou radicalizar a esse ponto. Mesmo porque prefiro analisar o sucesso das marcas a partir dos produtos ou serviços que estas traduzem. Se não há qualidade, inovação, um conceito sólido, não há programa de comunicação - seja de Relações Públicas, propaganda ou promoção - que consiga construir coisa alguma.

- Organicom - O planejamento estratégico e os resultados que se propõem estão associados com o fato de se ter princípios institucionais bem definidos?

- Gisele Lorenzetti - Há marcas que, além do investimento publicitário, têm 
seus preceitos e missão muito bem divulgados por ações de comunicação. Por exemplo, a Natura, que tem um conceito muito forte ligado ao meio ambiente. Outra empresa é a Gol, que preencheu um nicho, ingressou com ações na bolsa e está muito bem. Mas por quê? Tem um conceito, uma lógica, toda uma coerência de comunicação por trás. Acho fantástico o Magazine Luiza. Sou fã dessa mulher [Luiza Helena Trajano, superintendente]. O sucesso que ela tem hoje é conseqüência, pois tudo começou quando ela foi resgatar a dignidade do vendedor. Primeiro, ela mostrou que vendedor não é subemprego - muito pelo contrário: é quem ajuda as pessoas a realizarem sonhos. Depois disso, ter sucesso foi praticamente uma conse-

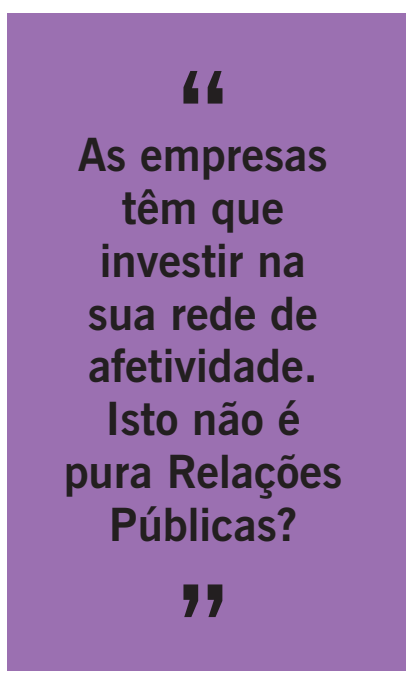
qüência. Hoje, existe muito mais essa consciência de um composto [da comunicação]. Parece que está claro que, antes de qualquer coisa, está o produto ou o serviço. A propaganda apresenta este produto e seus atributos e as ações de Relações Públicas dão consistência objetiva aos atributos apresentados pela propaganda.

- Organicom - Os consumidores modernos estão exigindo das empresas uma nova postura na prestação de serviços? Há mais espaço para o relacionamento hoje?
- Gisele Lorenzetti - A valorização de produtos e serviços que tenham uma atuação responsável social, ambiental e pessoalmente só tende a crescer. O Instituto Akatu, do Hélio Mattar [diretorpresidente], por exemplo, é uma ONG que trabalha pelo consumo consciente $\mathrm{e}$ eles usam uma expressão emocionante para nós da comunicação: as empresas têm que investir na sua rede de afetividade. Isto não é pura Relações Públicas? Hoje o consumidor está muito mais interessado em olhar o que está por trás do produto. As empresas serão reconhecidas não tanto pelo que falam de si mesmas, mas pelo que os terceiros - seus funcionários, seus fornecedores, sua comunidade e seus consumidores - falam delas. Isso é rede de afetividade, é consumo consciente e é para onde realmente as coisas caminham. E há marcas que quebram a cara quando erram nisso, como foi o caso da Nike.

- Organicom - E quanto à mudança de comportamento nas organizações? Estamos mesmo em um novo patamar da comunicação interna?

- Gisele Lorenzetti - Acredito que sim. Antes, vivíamos em um ambiente que nos ensinava a obedecer. O jornalzinho era "chapa branca" porque tínhamos isso como autoridade. Com a globalização, as coisas tenderam a mudar. Tivemos 
que começar a dialogar, a nos mostrar, a ter transparência, perguntar, responder, a falar e ouvir. As pessoas passam a ser fundamentais e aí mudou a relação com elas. Foi então que começou uma era da comunicação interna muito rica, ensaiando momentos de abertura, ações de comunicação, até por vezes com foco na relação pessoal deixando "papel" de lado como, por exemplo, os encontros com o presidente - o "você fala, ele responde" -, quando vai o repórter e câmera e abre para qualquer tipo de pergunta, sem edição, onde tudo é respondido. Entra-se, realmente, em um outro patamar, que também exige educação de ambas as partes. Não adianta só a empresa querer, o funcionário tem que começar a acreditar nessas ações também e isso também é um processo: a empresa deve insistir em falar, ser transparente e clara.

- Organicom - Ao longo da sua jornada, quais foram os maiores impactos no setor da Comunicação?

- Gisele Lorenzetti - A área de Comunicação sofreu bastantes modificações com os movimentos administrativos do final dos anos de 1980 e começo dos de 1990, principalmente o do downsizing. No final dos anos de 1980, terceirização e reengenharia começaram a ser vistas como forma de cortar custos, de mandar pessoas embora. Mas downsizing é outra coisa. A terceirização visa à especialização e à eficiência do serviço, quando ele não é o core business. Com a terceirização você ganha qualidade, eficiência e inteligência e ainda sorve conhecimento do outro. A terceirização foi fundamental para o setor das agên- cias de comunicação, porque a partir do momento em que as empresas deixaram de ter as suas estruturas e terceirizaram, começaram a buscar mais inteligência no prestador de serviço. E esse parceiro foi obrigado a trabalhar com base no planejamento, em gestão estratégica. E aí, ele que até então era um jornalista, algumas vezes infeliz por não ter seu espaço na redação, foi parar em uma agência e começou a ter de desenvolver uma visão maior de business, de gestão, de negócios. São cenários com que nos deparamos até hoje. Mas existiu uma resistência. Não vou dizer que todo prestador de serviço entendeu e se adaptou a esse momento. Foi uma migração lenta.

- Organicom - A partir de sua experiência, é importante passar por toda linha de produção de uma agência, fazer escola dentro dela?

— Gisele Lorenzetti - Não é mandatário ou fundamental, mas acho interessante. Temos que propor soluções diante do cliente e quando se conhecem os processos, há mais segurança no que se está propondo. Quando se vivencia menos esse processo, não quer dizer que não se conheça. Eu acho que não é necessário aprender a fazer de tudo para saber fazer ou orientar, mas se tem mais segurança na hora que propõe as soluções. É uma possibilidade construir a carreira conhecendo muito a operação, para depois se chegar no planejamento estratégico. São etapas ideais que você cumpre. É algo que você constrói.

- Organicom - E o que você dizia aos seus alunos? 


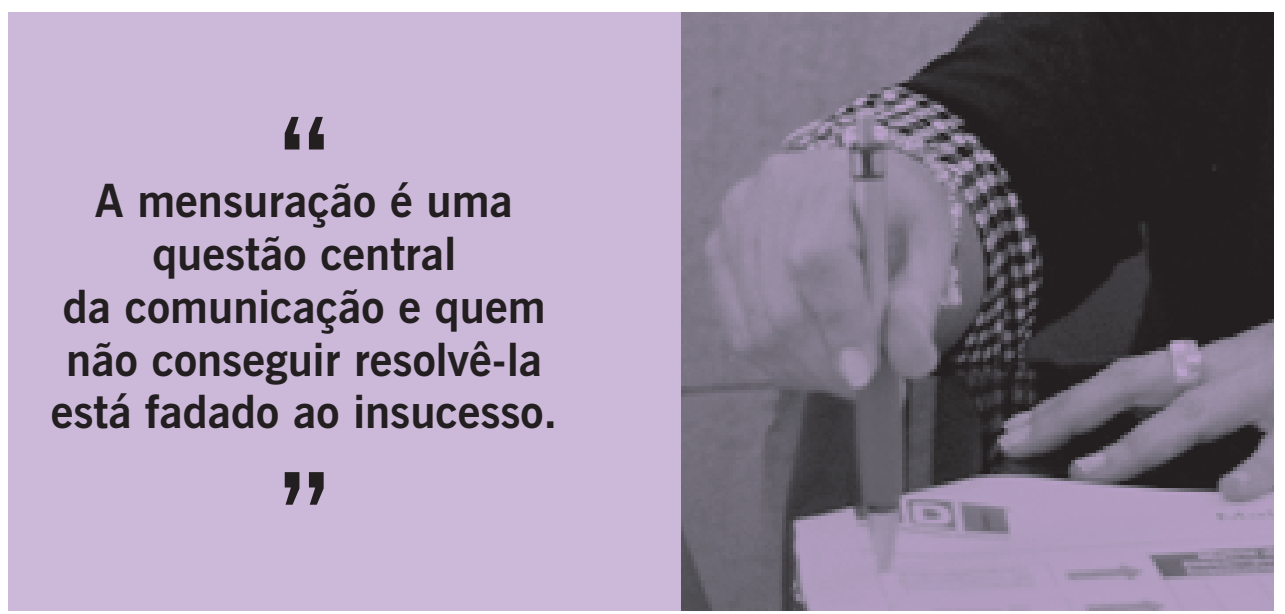

- Gisele Lorenzetti - Aos alunos de primeiro e segundo anos que queriam fazer estágio eu desaconselhava fazê-lo em agências. Recomendava fazer estágio em loja. Vai vender, mas não como sendo mais um vendedor na loja. Usa na loja toda sua técnica de comunicação, tudo o que está aprendendo na faculdade. Começa a analisar o perfil do público, a linguagem que tem que usar, o que é convencer, observar a reação das pessoas. Vá trabalhar em telemarketing, que é a melhor escola para se ouvir anseios e conhecer necessidades. No passado eu acreditava que a Faculdade estava muito distante do mercado, pois era muito teórica. Hoje penso bem diferente: acho a teoria fundamental. Ela ajuda a formar o profissional e o indivíduo. E se há um erro por parte das Faculdades é não contar aos alunos que, diferentemente do que aconteceu na vida daquele aluno até então, da faculdade ele pode esperar $60 \%$ de sua formação. $O$ resto iria depender dele, de seus esforços, interesses e buscas pessoais.

- Organicom - Na sua opinião, quais são as principais tendências da comunicação?

- Gisele Lorenzetti - Como disse anteriormente, não dá mais para vender nada não tangível, não mensurável. Hoje, tudo está muito ligado no resultado. Estamos cada vez mais falando de empresas de capital aberto, de megacorporações frutos de fusões. As empresas brasileiras também começam a abrir o capital onde a geração de valor ao acionista é tudo. Quando se fala disso, temos de falar de dinheiro, de comprovar resultados, de balanços. E se não se comprovar resultados, é claro que o gestor não vai destinar recurso para tal área. Ou seja, a mensuração é uma questão central da comunicação daqui para frente e quem não conseguir resolvê-la está fadado ao insucesso. 